\title{
MISI EMA (MIKROHIDRO IRIGASI UNTUK EKONOMI MANDIRI) PEMANFAATAN SALURAN IRIGASI SEBAGAI SUMBER ENERGI LISTRIK MANDIRI PADA BUDIDAYA BUNGA KRISAN DI "ASTHA BUNDA" KALIURANG
}

\author{
Dewi Triantini ${ }^{1}$, Haris Erdyanto ${ }^{2}$, Yoga Bagas $P^{3}$, Fruty Destiara $\mathbf{R}^{4}$, Rafika Febriantari ${ }^{5}$ \\ 1,2,3,4,5 Jurusan Pendidikan Teknik Elektro FT UNY \\ Email: dewianime98@gmail.com
}

\begin{abstract}
The cultivation of chrysanthemum flower has increased along with the increasing of domestic and international market's demand. This flowers need the lighting more than 13 hours/day to grow vegetatively, while in tropic area like Indonesia, it can't fulfilled because the sun only shine for 12 hours (average) so that it require the additional lighting which is sourced from high powered TL lamp. That additional lighting is required to 'create' long day in equator area around 3-4 hours with ligh intensity 32-108 lux. The most effective time to give the additional lighting is $10 \mathrm{pm}$ 'till $02 \mathrm{am}$. Watering with water pump has to be done routinely as of the cost of electricity increase. The cost of electricity in ASTHA BUNDA for a greenhouse is Rp.100.000/month. The goal of MISI EMA (Irrigation Microhydro for Independent Economy) is knowing MISI EMA design and work principle to help chrysanthemum farmer for supplying independent electricity source. The application of this technology is carried out at the association of chrysanthemum farmers ASTHA BUNDA in Jalan Kaliurang Km. 21 Pakembinangun, Pakem, Sleman The methods in this technology application program are analysis of field condition calculation, to design the device, to implement the device, and to monitor and evaluate the device performance to increase the productivity of chrysanthemum flowers. With this MISI EMA, electricity source for chrysanthemum flower can be covered. The cost of chrysanthemum flower production will be reduced because of the electricity source is not from PLN (State Electricity Enterprise) but it has been independent electricity source from MISI EMA
\end{abstract}

Keywords : Mikrohydro, Electricity source, Irigation

\begin{abstract}
ABSTRAK
Budidaya tanaman krisan meningkat seiring dengan meningkatnya permintaan pasar domestik maupun internasional terhadap bunga potong ini. Tanaman ini membutuhkan cahaya lebih dari 13 jam sehari untuk tetap tumbuh secara vegetatif, sedangkan didaerah tropis seperti Indonesia kebutuhan tersebut tidak dapat dipenuhi oleh cahaya matahari yang lamanya rata-rata 12 jam sehari sehingga perlu penambahan pencahayaan buatan yang bersumber dari lampu TL berdaya tinggi. Penambahan cahaya buatan untuk menciptakan kondisi hari panjang di daerah katulistiwa sekitar 3-4 jam dengan intensitas cahaya dengan kisaran 32-108 lux. Pemberian cahaya buatan paling baik antara pukul 22.00 sampai dengan 02.00 dini hari. Penyiraman dengan pompa air juga harus rutin dilakukan sehingga biaya pengeluaran listrik bertambah. Biaya pengeluaran listrik yang dikeluarkan oleh kelompok tani ASTHA BUNDA untuk setiap greenhouse rata-rata sebesar Rp.100.000 per bulan. Tujuan penerapan MISI EMA (Mikrohidro Irigasi untuk Ekonomi Mandiri), adalah untuk mengetahui desain alat MISI EMA, mengetahui unjuk kerja MISI EMA agar dapat membantu petani krisan dalam menyediakan sumber energi listrik mandiri. Penerapan teknologi ini dilaksanakan di asosiasi petani bunga krisan ASTHA BUNDA Jalan Kaliurang Km. 21 Desa Pakembinangun, Kecamatan Pakem, Sleman. Metode dalam program penerapan teknologi ini yaitu melakukan analisis perhitungan kondisi lapangan, melakukan perancangan, implementasi alat, monitoring dan evaluasi. Melalui alat MISI EMA ini, sumber tenaga listrik untuk kebutuhan bunga krisan di ASTHA BUNDA bisa dicover. Nantinya biaya produksi bunga krisan akan tereduksi karena sumber tenaga listrik tidak lagi membeli dari PLN melainkan sumber daya listrik yang mandiri dengan MISI EMA.
\end{abstract}

Kata kunci : Mikrohidro, Sumber Listrik, Irigasi 


\section{PENDAHULUAN}

Bunga Krisan merupakan komoditi yang dibudidayakan oleh kelompok tani ASTHA BUNDA. Tanaman krisan merupakan salah satu jenis bunga potong yang bukan asli dari Indonesia. Akan tetapi bunga potong ini telah melanglang buana ke seluruh penjuru negeri. Di Indonesia, tanaman krisan disebut juga bunga seruni atau dalam bahasa latinnya yaitu Chrysanthemum sp. Dewasa ini minat petani untuk membudidayakan tanaman krisan secara komersial meningkat seiring dengan meningkatnya permintaan pasar domestik maupun internasional terhadap bunga potong ini (Direktorat Budidaya Tanaman Krisan, 2007).

Krisan merupakan tanaman hari pendek yang inisiasi dan perkembangan bunganya dikendalikan oleh panjang hari. Tanaman ini membutuhkan cahaya lebih dari 13 jam sehari untuk tetap tumbuh secara vegetatif. Di daerah tropis seperti Indonesia kebutuhan tersebut tidak dapat dipenuhi oleh cahaya matahari yang lamanya rata-rata 12 jam sehari sehingga perlu ditambah dengan pencahayaan buatan dari lampu listrik yang biasanya dilakukan setelah matahari terbenam. Menurut Fides (1992) penambahan cahaya buatan untuk menciptakan kondisi hari panjang di daerah katulistiwa sekitar 3-4 jam dengan intensitas cahaya dengan kisaran 32-108 lux. Pemberian cahaya buatan paling baik ialah antara pukul 22.00 sampai dengan 02.00 dini hari (Van Sluis, 1952). Manipulasi panjang hari dapat dilakukan dengan menggunakan cahaya dari sumber lampu pijar maupun lampu tabung (Kofranek, 1980).

ASTHA BUNDA adalah kelompok tani yang ada di wilayah lereng gunung Merapi, tepatnya di Kaliurang, Sleman, DIY yang membudidayakan bunga Krisan. Kelompok tani ASTHA BUNDA beranggotakan 22 anggota kelompok tani bunga krisan yang aktif. Setiap minggunya kelompok tani ASTHA BUNDA melakukan penanaman kurang lebih 10.000 batang dalam satu green house. Jumlah produksi ini masih sangat kurang untuk memenuhi permintaan pasar di DIY. Pembeli hasil panen bunga Krisan dari kelompok tani ini dari berbagai kalangan seperti hotel, rumah makan, kantor, dan perakit karangan bunga serta masyarakat umum di DIY. Selain untuk memenuhi kebutuhan bunga Krisan di DIY saja yang belum mencukupi, pasar dari bunga Krisan ini juga masih sangat terbuka lebar untuk daerah lainnya terutama daerah Jawa Tengah.

Menurut penuturan salah seorang petani ASTHA BUNDA pencahayaan tambahan menjadi masalah tersendiri karena petani bunga krisan hanya mengandalkan lampu TL berdaya tinggi untuk mendapatkan lux yang tepat bagi pertumbuhan bunga krisan, selain itu penyiraman dengan pompa air juga harus rutin dilakukan, akibatnya biaya pengeluaran untuk listrik yang dibutuhkan pun bertambah. Biaya pengeluaran listrik yang dikeluarkan oleh kelompok tani ASTHA BUNDA untuk setiap greenhouse rata-rata sebesar Rp.100.000 per bulan. Biaya pengeluaran untuk listrik tersebut membuat keuntungan yang didapatkan petani krisan menjadi sangat kecil. Hal tersebut dialami pula oleh petani lainnya di Asosiasi Tanaman Hias Bunga Krisan ASTHA BUNDA Desa Pakembinangun Kecamatan Pakem Sleman. Dalam hal ini kami memberikan solusi dengan pembuatan pembangkit listrik berefisiensi tinggi memanfaatkan saluran irigasi yang berada di daerah tersebut untuk membantu petani bunga krisan ASTHA BUNDA dalam mengurangi biaya produksi agar keuntungan petani semakin meningkat.

\section{METODE}

Penelitian ini dilaksanakan pada bulan April sampai Juli 2018. Lokasi penelitian ini dilaksanakan di Asosiasi Tanaman Hias Bunga 
dan Daun (ASTHA BUNDA) yang beralamat di Jalan Kaliurang $\mathrm{Km}$ 21, Desa Pakembinangun, Kecamatan, Pakem, Sleman, Yogyakarta.

Proses perancangan desain penerapan MISI EMA dilakukan setelah mengkaji kondisi lapangan di kebun milik salah satu anggota kelompok tani ASTHA BUNDA yang memiliki luas $25 \mathrm{~m}^{2} /$ petak dari luas $\pm 200-400$ $\mathrm{m}^{2} /$ greenhouse agar nantinya alat ini benarbenar dapat berkerja efektif.

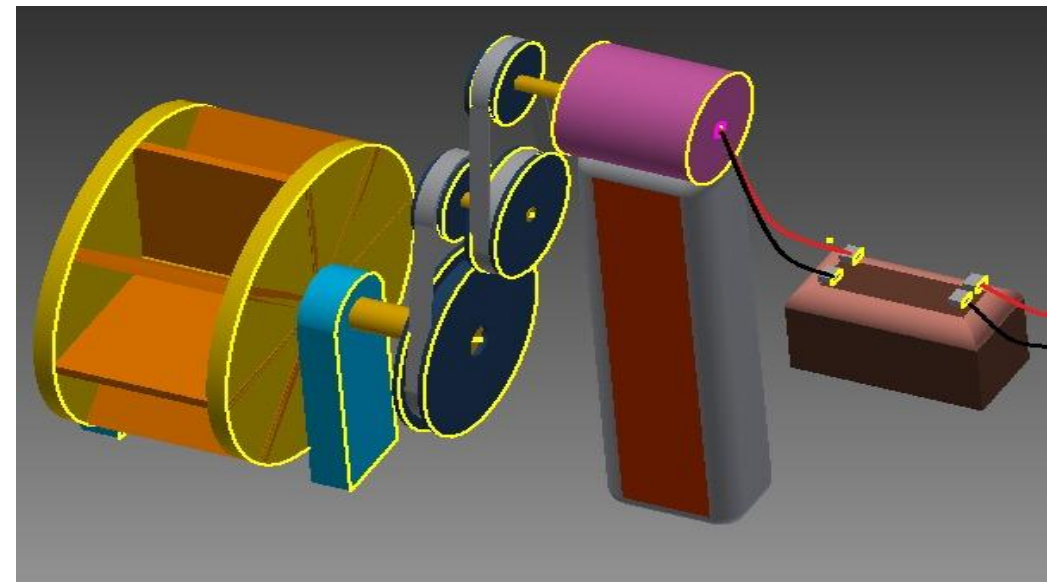

Gambar 1. Desain Alat
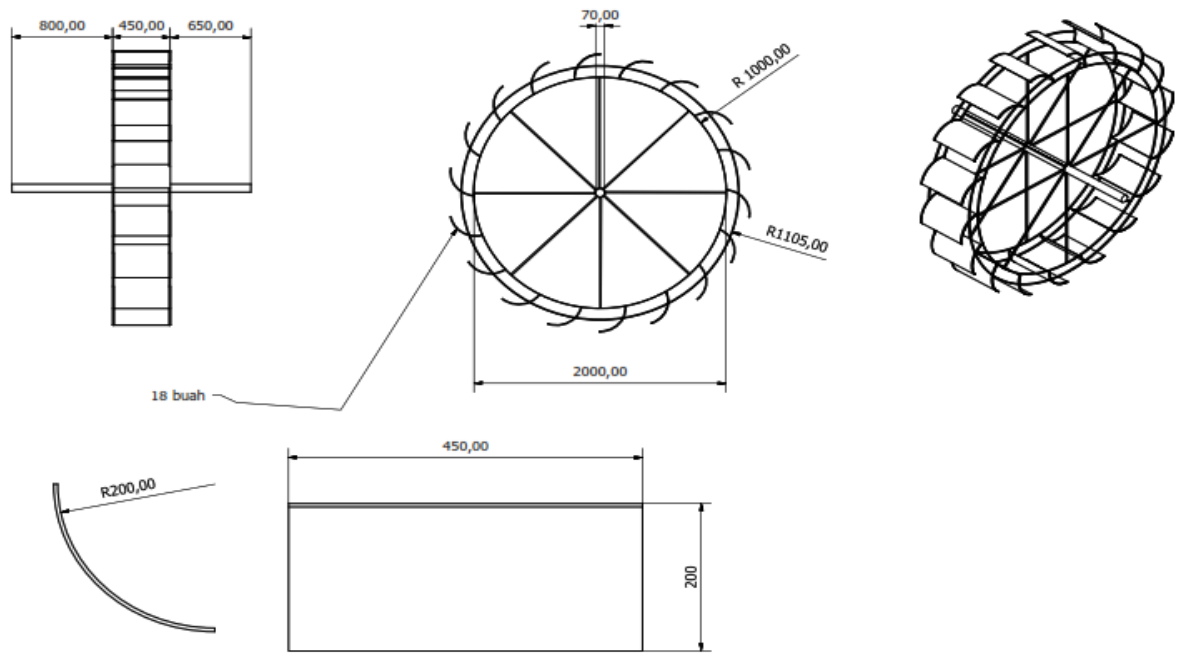

Gambar 2. Desain Kincir

Tahap persiapan umum ini meliputi kunjungan mitra ke asosiasi tani ASTHA BUNDA Kaliurang, studi pustaka, konsultasi dengan ahli, perancangan MISI EMA, dan menganalisis kebutuhan alat dan bahan.

Kunjungan mitra ke ASTHA BUNDA ini bertujuan untuk meninjau ulang penerapan PKM-T serta menjalin komunikasi yang baik dengan mitra. Kemudian dilakukan konsultasi dengan ahli untuk mendapatkan saran yang terbaik dalam membuat MISI EMA sebagai solusi dari permasalahan mitra. Perancangan desain MISI EMA dilakukan dengan analisis yang matang agar nantinya produk yang dibuat sesuai dengan target luaran dan kondisi lapangan. Setelah desain didapatkan, langkah selanjutnya adalah menganalisis kebutuhan alat dan bahan yang sesuai. Kemudian dilakukan pembelian alat dan bahan untuk proses pembuatan dan implementasi MISI EMA.

Pembuatan alat dimulai dengan pembuatan kincir yang mana sudah dirancang desainnya dengan matang berdasarkan kondisi lapangan dan kajian pustaka. Kincir tersebut 
memiliki diamater sebesar $200 \mathrm{~cm}$ dan lebar sebesar $45 \mathrm{~cm}$. Sirip kincir yang didesain melengkung ditujukan untuk memperbesar kekuatan desain kincir air tipe undershoot yang sesuai dengan karakteristik saluran irigasi di lokasi penerapan alat. Setelah kincir jadi, maka dilakukan perakitan, yaitu pemasangan kincir dengan komponen yang lainnya yaitu seperti pulley, belt, alternator, konverter, dan sebagainya hingga akhirnya alat siap untuk diimplementasikan di lokasi mitra (saluran irigasinya).

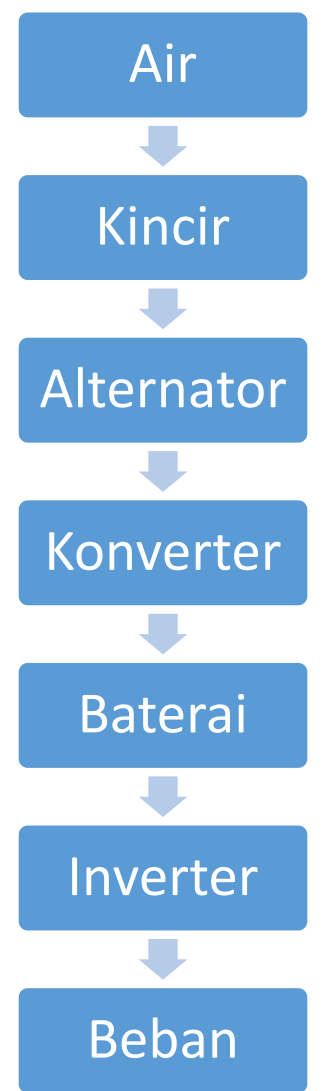

Gambar 3. Alur Kerja Alat

Analisis Perhitungan

\begin{tabular}{|l|l|}
\hline \multicolumn{2}{|c|}{ Data } \\
\hline Kecepatan (v) & $5,97 \mathrm{~m} / \mathrm{s}$ \\
\hline Diameter roda air (D) & $2 \mathrm{~m}$ \\
\hline Lebar sudu bengkok (Is) & $0,348 \mathrm{~m}$ \\
\hline $\begin{array}{l}\text { Kedalaman air di saluran } \\
\text { (d) }\end{array}$ & $0,27 \mathrm{~m}$ \\
\hline $\begin{array}{l}\text { Lebar saluran yang } \\
\text { terbasahi (w) }\end{array}$ & $0,45 \mathrm{~m}$ \\
\hline
\end{tabular}

Berdasarkan data-data yang diperoleh dari hasil pengamatan di lapangan, maka dilakukanlah beberapa perhitungan:

a. Perhitungan Kincir

$$
\begin{aligned}
& D=D_{\text {velk }}+2 x I_{s}=2+2 x 0,348=2,696 \\
& \mathrm{~m} \\
& \mathrm{r}=\frac{1}{2} \mathrm{D}=\frac{1}{2} \times 2=1 \mathrm{~m} \\
& n_{p}=\frac{v 60}{2 \pi r}=\frac{5,97 \cdot 60}{2 \cdot 3,14 \cdot 1}=57,03 \mathrm{rpm}
\end{aligned}
$$

b. Perhitungan pada Pulley

$n_{p}=w_{1}=57,03 \mathrm{rpm}$

$r_{1}=20 \mathrm{~cm}, r_{2}=3,75 \mathrm{~cm}, r_{3}=10 \mathrm{~cm}, r_{4}=$ $2,5 \mathrm{~cm}$

$w_{1} \cdot r_{1}=w_{2} \cdot r_{2}=>57,03 \cdot 20=w_{2} \cdot 3,75$

$1140,6=3,75 w_{2}$

$\mathbf{3 0 4 , 1 6} \mathbf{~ r p m}=w_{2}$

$w_{2}=w_{3}=304,16 \mathrm{rpm}$

$w_{3} \cdot r_{3}=w_{4} \cdot r_{4}=>304,16 \cdot 10=w_{4} \cdot 2,5$

$3041,6=2,5 w_{4}$

$1216,64 \mathrm{rpm}=w_{4}$

c. Perhitungan Daya yang Dihasilkan

$$
\begin{aligned}
F_{1} & =50 \mathrm{~N} \quad F_{2}=400 \mathrm{~N} \\
F_{3} & =285 \mathrm{~N} \quad F_{4}=48 \mathrm{~N} \\
T_{1} & =\left(F_{2}-F_{1}\right) r_{x}=(400-50) 0,0375 \\
& =350.0,0375=13,125 \mathrm{Nm}
\end{aligned}
$$

Keterangan :

$I_{S}=$ lebar sudu bengkok $(\mathrm{m})$

$n_{p}=w_{1}=$ putaran poros roda air $(\mathrm{rpm})$

$r=$ jari-jari kincir dan jari-jari pulley (m)

$F=$ gaya pada roda air $(\mathrm{N})$

$T=$ Torsi pada poros $(\mathrm{Nm})$

$\eta=$ Efisiensi 


$$
\begin{aligned}
& W=\text { massa jenis air } \mathrm{kg} / \mathrm{m}^{3} \\
& Q=\operatorname{Debit} \operatorname{air}\left(\mathrm{m}^{3} / \mathrm{s}\right) \\
& \mathrm{H}=\operatorname{ketinggian}(\mathrm{m})
\end{aligned}
$$

Kincir air MISI EMA dipasang pada saluran irigasi yang terdapat di depan kebun bunga krisan mitra, sedangkan untuk sistem kelistrikannya diletakkan di dalam greenhouse guna mengurangi kerusakan komponen akibat korosi. Saluran irigasi tersebut memiliki tinggi $65 \mathrm{~cm}$ dan lebar $60 \mathrm{~cm}$, dengan debit rata-rata 50 1/s. Setelah alat diimplementasikan, diadakan monitoring rutin satu minggu sekali untuk memantau unjuk kerja dan kendala dari MISI EMA. Jika terdapat ketidaksesuaian maka dilakukan evaluasi dan perbaikan untuk meningkatkan kinerja MISI EMA agar dapat bekerja secara optimal.

\section{HASIL DAN PEMBAHASAN}

Berdasarkan hasil implementasi alat diperoleh hasil sebagai berikut:

\section{Pembangkit Listrik}

Program ini menghasilkan hasil luaran berupa alat pembangkit listrik berefisiensi tinggi yang telah dibuktikan dengan daya listrik yang dihasilkan sebesar 220 Watt. Daya tersebut cukup untuk kebutuhan listrik pada satu greenhouse bunga krisan. Efisiensi tinggi tersebut didapatkan dari desain kincir yang menyerupai roda traktor dengan sirip melengkung dan bahan kincir yang cukup ringan sehingga perputaran yang dihasilkan maksimal.

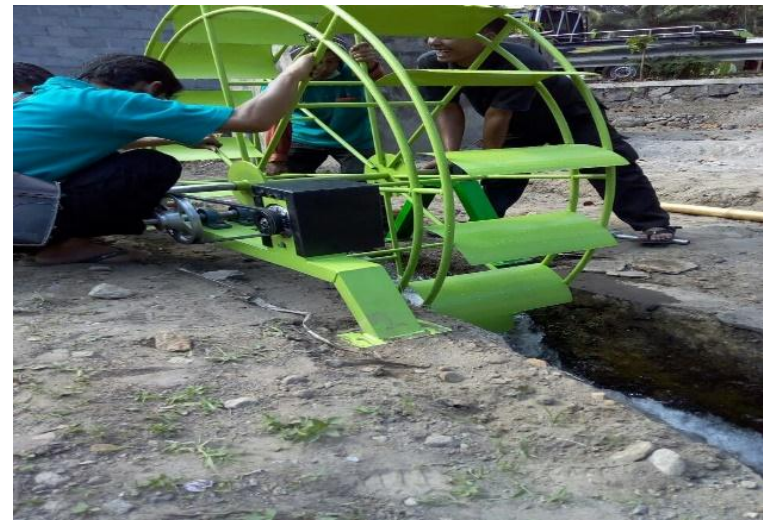

Gambar 4. Misi EMA

\section{Kebutuhan Listrik}

Karakteristik bunga krisan yang bukan termasuk tanaman asli Indonesia mengaharuskan adanya perlakuan khusus terhadap tanaman ini, yaitu terutama masalah pencahayaan tambahan. Pencahayan tambahan dilakukan dengan penyinaran menggunakan lampu soft light dengan daya total 210 Watt setiap greenhouse. Sumber tenaga listrik yang dipakai oleh petani krisan berasal dari PLN. Rata-rata pemakaian listrik untuk satu greenhouse adalah Rp. 100.000,-. Melalui alat MISI EMA ini, sumber tenaga listrik untuk kebutuhan bunga krisan di ASTHA BUNDA bisa dicover. Nantinya biaya produksi bunga krisan akan tereduksi karena sumber tenaga listrik tidak lagi membeli dari PLN melainkan sumber daya listrik yang mandiri dengan MISI EMA.

\section{SIMPULAN}

Dari hasil implementasi alat MISI EMA didapatkan kesimpulan: 1) MISI EMA merupakan pembangkit listrik tenaga air saluran irigasi, 2) MISI EMA dapat menghasilkan daya output sebesar 220 Watt, 3) Pengeluaran untuk kebutuhan listrik Rp. 100.000,- bisa dihilangkan dengan adanya MISI EMA. 


\section{DAFTAR RUJUKAN}

Direktorat Budidaya Tanaman Hias. 2007.

Standar Operasional Prosedur Budidaya Krisan. Jakarta: Departemen Pertanian.

Kofranek, A. M. 1980. Cut Crysanthemum, In R. A. Larson (ed). Introduction to
Floriculture. Academic Press, Inc. New York.

Setyono et al. 2011. Rehabilitasi Usahatani Bunga Krisan Pasca Erupsi Gunung Merapi. Yogyakarta: BPTP Dipertan. 